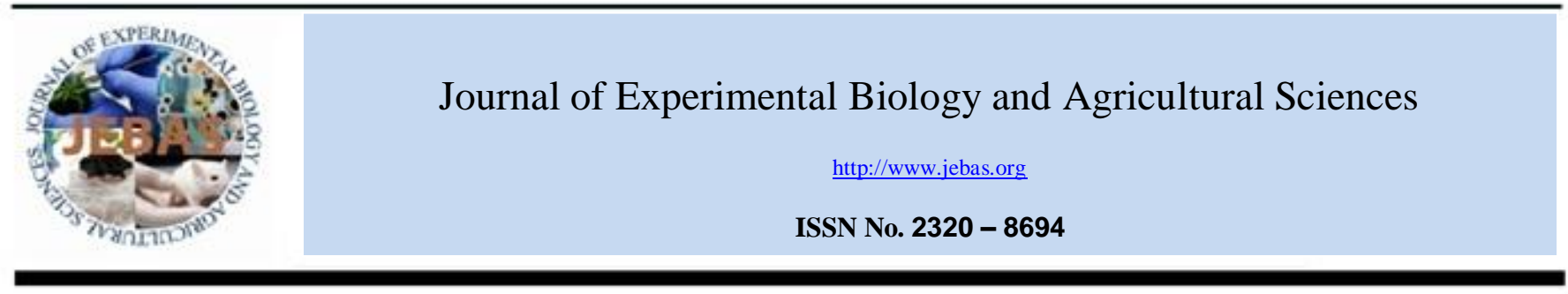

\title{
IMPACT OF MASS MEDIA EXPOSURE AND INNOVATION PRONENESS ON COCOON PRODUCTION
}

\author{
Mir M A ${ }^{1}$, Baqual $\mathrm{M} \mathrm{F}^{1, *}$, Kamili $\mathrm{AS}^{2}$, Mir S A ${ }^{3}$, Sakiba Saleem ${ }^{1}$ and Verma G R \\ ${ }^{1}$ Temperate Sericulture Research Institute, SKUAST-K, Shalimar, Mirgund Baramulla Kashmir, India \\ ${ }^{2}$ Directorate of Extension, SKUAST-K, Shalimar, Mirgund Baramulla Kashmir, India \\ ${ }^{3}$ Division of Agri- statistics SKUAST-K, Shalimar, Mirgund Baramulla Kashmir, India \\ ${ }^{4}$ Degree college Udampur, Kashmir, India
}

Received - April 17, 2015; Revision - September 21, 2015; Accepted - October 13, 2015

Available Online - October 20, 2015

DOI: http://dx.doi.org/10.18006/2015.3(5).453.457

KEYWORDS
Change proneness
Cocoon marketing
Mass media
Kashmir valley

\begin{abstract}
A total of 75 farmers were selected from the four sericulturally important districts viz., Kupwara, Baramulla, Budgam and Pulwama of Kashmir valley (India) to study the impact of mass media exposure and changing proneness on the cocoon marketing and cocoon production. Results of study indicated that 58.67 per cent of the respondents had low exposure to mass media, while 34 per cent of them had medium level exposure and only 7.33 per cent enjoyed high level exposure. Change proneness status of stakeholders revealed that overall 50 per cent of respondents belonged to medium category of change proneness; this was followed by low category (42\%) and high category $(8 \%)$ respectively. With respect to marketing, 67.67 percent of the studied farmers complained about delayed marketing and only 26 per cent of them were satisfied with present marketing operations. Although 51 per cent of the farmers expressed that markets were established in the vicinity of district headquarters, yet 49 per cent were not satisfied with the location of market. Furthermore 90.67 per cent of beneficiaries expressed their displeasure over the competitiveness of marketing and as a result of poor marketing, while 77.67 percent of the rearers expressed that they were not getting remunerative prices for the final produce. On cocoon production side, majority of respondents (72\%) fall into low category whereas 22.33 and 5.67 percent of them were reported in medium and high category of cocoon production respectively. The cocoon productivity figures also revealed that 30.33 percent of respondents of study area harvested $6-31 \mathrm{~kg}$ of green cocoons/ounce of silkworm seed, while $61 \%$ percent harvested $31.56 \mathrm{~kg} /$ ounce whereas only 8.67 per cent of them harvested $56-81 \mathrm{~kg}$ of cocoons/ounce of seed.
\end{abstract}

* Corresponding author

E-mail: fbaqual@rediffmail.com (Baqual M F)

Peer review under responsibility of Journal of Experimental Biology and Agricultural Sciences.

Production and Hosting by Horizon Publisher (www.myvision.webs.com/horizon.html).

All rights reserved.
All the article published by Journal of Experimental Biology and Agricultural Sciences is licensed under a Creative Commons Attribution-NonCommercial 4.0 International License Based on a work at www.jebas.org.

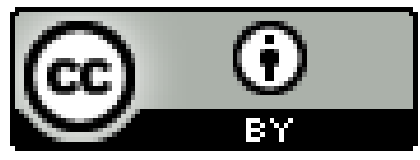




\section{Introduction}

The word silk which carries with it the sense of elegance is considered to be the queen of textiles and the various garments woven out of silk are used throughout the world, thus paving way for its increased production with every passing day. The major silk producing countries in the world are China, India, Uzbekistan, Brazil, Japan, Republic of Korea, Thailand, Vietnam, DPR Korea, Iran, etc. Whereas few other countries like Kenya, Botswana, Nigeria, Zambia, Zimbabwe, Bangladesh, Colombia, Egypt, Japan, Nepal, Bulgaria, Turkey, Uganda, Malaysia, Romania, Bolivia etc are also engaged in the production of cocoons and raw silk in negligible quantities.

India is one of the major silk producing countries and silk Industry provides employment to 7.9 million people in India being the world's second largest producer. Sericulture can help employing the rural population and prevent their migration to big cities (CSB, http://inserco.org/en/?q=statistics). Annual silk production of the country on an average is about 20,000 MT, while total annual consumption of silk is around 29,000 MT, thereby creating a deficit of 9000 MT of silk which again calls for increase in production through plan periods (Giridhar et al., 2011).

The state of Jammu and Kashmir is northern state of India having subtropical climate. State has distinction of being the only natural bi-voltine silk producing belt in India. The cocoon production during the year 1940 had registered all time high viz., 15MT, when 52000 families were attached with it (State Sericulture Department, http://jksericulture.nic.in/2. The association of farmer's extension contact with adoption index is highly positive and also the mass media participation helps farmers to adopt the technologies either fully or partially (Srinivasa et al., 1998). Furthermore, the extension agents need to recognize the factors and arrange suitable educational activities by way of group discussions, farm visits, training and demonstrations to cater to the needs of people for development of sericulture (Gopala et al., 1992; Sinha et al., 1995).

A study on adoption of recommended mulberry cultivation practices made by Sujatha et al. (2006) suggested that the variables such as education, experience in sericulture, social participation, mass media participation, extension participation, extension contact, material possession, net income and credit facilities were found to have positive impact with significant relationship with the adoption while age had a negative relationship with it. Similarly the results obtained by Halakatti et al. (2010) suggested that television was most sought after mass media source $(75 \%)$ and it was followed by radio $(65 \%)$. Highest percentage of agricultural information adopted was obtained through television $(40.75 \%)$ followed by radio $(32.25 \%)$.
Jayaram \& Indumeti (2010) while studying the awareness and attitude of farmers associated with sericulture observed a significant relationship between knowledge level and education, total land holding, extension contact, social participation and cocoon yield. Variables like age, education, extension participation and extension contact, mass media exposure, social participation and risk orientation had significant association with knowledge and adoption level of respondents (Shilpa et al., 2011). Since practice of sericulture in the valley of Kashmir is subsidiary and where only monocropping is practised, it becomes very important to boost cocoon production and single out the reasons which might play the negative role in increasing the productivity. As such the possible role of these determinants in the production of cocoons in Kashmir valley which has not been worked out till date would throw open fruitful information for the sustenance of farmers associated with the sericulture industry.

\section{Materials and methods}

Present investigation was carried out during 2011-12 in four districts namely Kupwara, Baramulla, Budgam and Pulwama representing northern, central and southern parts of the Kashmir valley respectively. The data were collected on preformulated questionnaire/schedule which was divided into three main parts viz. part A, part B and part C. Part A was further sub-divided into nine sub-parts for extracting information like general information, educational status, family, number of persons involved in sericulture, experience (years), primary occupation, extension contact, mass media exposure and change innovation proneness. Mass media exposure has been calculated by 3, 2, 1 and 0 scores for daily, often, rarely and never regarding listening radio, reading magazines and newspapers and seeing $T$.V. programmes related to sericulture, while as the scores 3,2 and 1 correspond to within last six months, between 6 months to 1 year and between 1 year to 2 years, respectively in case of farm magazine subscription and attending Kisan Melas or Farm Visits, etc. and finally mass media exposure was calculated in percentage using the following formula 1.1 .

Change proneness refers to the disposition of an individual to accept or reject a change. The innovation proneness was measured by using self rating scale developed by Moulik \& Rao (1965). The scale consisted of three items and each item has three parts with varying degree of innovation proneness. The responses were checked by simply reading of the statements of liking whether they like or not, particular statement of change proneness. The most like statements were awarded a score of 2 and the least like as 1 . In this way, most like scores were multiplied by their corresponding scale values and least like statements by their corresponding scale values as shown in Appendix-III. Innovation proneness for each individual was calculated by using the formula 1.2. 


\begin{tabular}{|c|c|c|c|}
\hline \multirow{2}{*}{ Mass media exposure $(\%)=$} & Total score obtained & \multirow{2}{*}{$\mathbf{x} 100$} & \multirow{2}{*}{... Formula 1.1} \\
\hline & Maximum score obtainable & & \\
\hline \multirow{2}{*}{ Innovation Proneness = } & Sum of ratios of most like statements & & \multirow{2}{*}{... Formula 1.2} \\
\hline & Sum of ratios of least like statements & & \\
\hline
\end{tabular}

However, marketing part which was based on six questions answered by the respondents either in the form of 'Yes' or 'No' only. The sampling plan used in the present study was based on multi-stage sampling in which four sericulturally rich districts viz. Kupwara, Baramulla, Budgam and Pulwama were used. From each district, three tehsils were also selected on the basis of purposive sampling to cover the requisite number of villages.

Part B of the interview schedule consisted of questions regarding various technologies generated by two important sericulture research Institutes viz. Temperate Sericulture Research Institute, Mirgund and Central Sericultural Research Institute, Pampore, Kashmir where as part $\mathrm{C}$ of the interview schedule consisted of the constraints related to low production/productivity of cocoons in the target area.

\section{Results and Discussion}

Majority of the respondents in the present study were illiterate and they had taken sericulture as a subsidy occupation for earning their livelihood. Because they are illiterate so they cannot read newspapers and magazines related to sericulture, which is evident that 58.67 percent respondents were possessing low mass media exposure (Table-1) and only 22 out of 300 respondents were having high level of mass media exposure owing to their educational background. Due to low level of mass media exposure and strong traditional beliefs, around 92 percent respondents on cumulative basis were not either willing or half-hearted to accept innovation or change that could be one of the reasons for low production/ productivity of cocoons in Kashmir valley (Table 2). The tendency of showing no attention towards innovation or change proneness might be due to their decreased literacy rate and no contact with mass media and other extension agencies. This in turn might have resulted in their increased association with ethical and traditional beliefs and thus dreaded productivity levels.

All the respondents under study do not sell their produce immediately after harvest because the marketing of cocoons starts atleast one month later resulting in the deterioration of cocoons during their post harvest storage. Half of the respondents claimed that they were not in vicinity from the marketing headquarters, thereby increasing the transportation costs resulting in low benefit/cost ratio (Table-3). Around $3 / 4^{\text {th }}$ respondents were not satisfied with the marketing of cocoons due to lack of competition in marketing $(90.67 \%$ respondents) and less remunerative prices $(77.67 \%$ respondents). The delayed marketing of cocoons, coupled with establishment of such markets for away from rearing zones might also disinterest the reaers and result in their decreased participation with silk cocoon rearing. Similar results were also obtained by Dhane \& Dhane (2004).

The performance of respondents regarding cocoon production was not satisfactory as 72 percent of respondents belonged to low production category of 6 to $54 \mathrm{~kg}$ of cocoons (Table-4). The reasons for low production might be the lack of rearing houses coupled with leaf shortage as expressed by most of the respondents.

Table 1 Percent mass media exposure status of respondents in selected districts.

\begin{tabular}{|c|c|c|c|c|c|c|}
\hline \multicolumn{2}{|c|}{ Class $(\%)$} & Category & Kupwara & Baramulla & Budgam & Pulwama \\
\hline $0-20$ & Low & $53(70.67)$ & $37(49.33)$ & $35(46.67)$ & $51(68.00)$ & $176(58.67)$ \\
\hline $21-40$ & Medium & $17(22.67)$ & $36(48.00)$ & $28(37.33)$ & $21(28.00)$ & $102(34.00)$ \\
\hline \hline $41-60$ & High & $5(6.66)$ & $2(2.67)$ & $12(16.00)$ & $3(4.00)$ & $22(7.33)$ \\
\hline
\end{tabular}

All values are expressed as number of respondents; Figures in parenthesis indicate $\%$ of respondents; $\mathrm{N}=$ Number of respondents (75 for each group).

Table 2 Change/innovation proneness status of respondents in selected districts.

\begin{tabular}{|c|c|c|c|c|c|c|}
\hline \hline Class (change proneness) & \multicolumn{1}{c}{ Category } & \multicolumn{2}{c}{ Kupwara } & \multicolumn{1}{c|}{ Baramulla } & Budgam & \multicolumn{1}{c|}{ Pulwama } \\
\hline $0-1.5$ & Low & $37(49.33)$ & $25(33.33)$ & $31(41.33)$ & $33(44.00)$ & $126(42.00)$ \\
\hline $1.51-3$ & Medium & $36(48.00)$ & $39(51.00)$ & $38(50.67)$ & $37(49.33)$ & $150(50.00)$ \\
\hline \hline $3.1-4.5$ & High & $2(2.67)$ & $11(14.67)$ & $6(8.00)$ & $5(6.67)$ & $24(8.00)$ \\
\hline
\end{tabular}

All values are expressed as number of respondents; Figures in parenthesis indicate \% of respondents; $\mathrm{N}=$ Number of respondents (75 for each group) 
Table 3 Production $(\mathrm{kg})$ of green cocoons by respondents in selected districts.

\begin{tabular}{|l|c|c|c|c|c|c|}
\hline Class $(\mathrm{kg})$ & Category & Kupwara & Baramulla & Budgam & Pulwama \\
$\mathbf{6 - 5 4}$ & Low & $61(81.34)$ & $50(66.67)$ & $16(21.33)$ & $24(32.67)$ & $24(72.00)$ \\
\hline $\mathbf{5 5 - 1 0 2}$ & Medium & $13(17.33)$ & $9(12.00)$ & $4(5.33)$ & $14(18.67)$ \\
\hline \hline $\mathbf{1 0 3 - 1 5 0}$ & High & $1(1.33)$ & $97(22.33)$ & $3(4.00)$ \\
\hline
\end{tabular}

All values are expressed as number of respondents; Figures in parenthesis indicate $\%$ of respondents; $\mathrm{N}=$ Number of respondents $(75$ for each group)

Table 4 Productivity (kg/ounce) of green cocoons in selected district.

\begin{tabular}{|c|c|c|c|c|c|c|}
\hline Class (kg/ ounce) & Category & Kupwara & Baramulla & Budgam & Pulwama & Total \\
\hline $6-31$ & Low & $27(36.00)$ & $30(40.00)$ & $7(9.33)$ & $27 \quad(36.00)$ & $91(30.33)$ \\
\hline $32-56$ & Medium & $44(58.67)$ & $30(40.00)$ & $64(85.34)$ & $45(60.00)$ & $183(61.00)$ \\
\hline $57-81$ & High & $4(5.33)$ & $15(20.00)$ & $4(5.33)$ & $3(4.00)$ & $26(8.67)$ \\
\hline
\end{tabular}

All values are expressed as number of respondents; Figures in parenthesis indicate $\%$ of respondents; $\mathrm{N}=$ Number of respondents ( 75 for each group)

Table 5 Response of stakeholders towards marketing of cocoons in selected districts.

\begin{tabular}{|c|c|c|c|c|c|c|c|c|c|c|c|}
\hline \multirow[t]{2}{*}{ S. No. } & \multirow[t]{2}{*}{ Parameter } & \multicolumn{2}{|c|}{ Kupwara } & \multicolumn{2}{|c|}{ Baramulla } & \multicolumn{2}{|c|}{ Budgam } & \multicolumn{2}{|c|}{ Pulwama } & \multicolumn{2}{|c|}{ Total } \\
\hline & & Yes & No & Yes & No & Yes & No & Yes & No & Yes & No \\
\hline 1. & Immediate marketing & $0(0.00)$ & $75(100)$ & $0(0.00)$ & $75(100)$ & $0(0.00)$ & $75(100)$ & $0(0.00)$ & $75(100)$ & $0(0.00)$ & $300(100)$ \\
\hline 2. & Post harvest damage to cocoons & $53(70.67)$ & $22(29.33)$ & $46(61.33)$ & $29(38.67)$ & $49(65.33)$ & $26(34.67)$ & $55(73.33)$ & $20(26.67)$ & $203(67.67)$ & $97(32.33)$ \\
\hline 3. & Vicinity from marketing head quarter & $33(44.00)$ & $42(56.00)$ & $18(24.00)$ & $57(76.00)$ & $48(64.00)$ & $27(36.00)$ & $54(72.00)$ & $21(28.00)$ & $153(51.00)$ & $147(49.00)$ \\
\hline 4. & Satisfied marketing of cocoons & $25(33.33)$ & $50(66.67)$ & $14(18.67)$ & $61(81.33)$ & $21(28.00)$ & $54(72.00)$ & $18(24.00)$ & $57(76.00)$ & $78(26.00)$ & $222(74.00)$ \\
\hline 5. & Competitive marketing & $10(13.33)$ & $65(86.67)$ & $5(6.67)$ & $70(93.33)$ & $6(8.00)$ & $69(92.00)$ & $7(9.33)$ & $68(90.67)$ & $28(9.33)$ & $272(90.67)$ \\
\hline 6. & Remunerative price for final produce & $23(30.67)$ & $52(69.33)$ & $12(16.00)$ & $63(84.00)$ & $18(24.00)$ & $57(76.00)$ & $14(18.67)$ & $61(81.33)$ & $67(22.33)$ & $233(77.67)$ \\
\hline
\end{tabular}

All values are expressed as number of respondents; Figures in parenthesis indicate $\%$ of respondents; $\mathrm{N}=$ Number of respondents ( 75 for each group) 
Non/partial availability of basic infrastructure seems to be the major reason responsible for low productivity as around 91.33 percent respondents produced below $56 \mathrm{~kg}$ of cocoons per ounce of silkworm seed which is the national average. The low level of technology adoption during rearing period results in great loss of final produce due to mortality of larvae and formation of flimsy and deformed cocoons. Low level of mass media exposure, extension contact and change proneness are also equally responsible for both low production and productivity of cocoons. In the state of $J \& K$, farmers do not have the separate rearing houses for rearing silkworm and as such they rear their silkworms in dwelling houses which essentially a rearing cum dwelling house. Presence of heavy inoculum load and hesitation of some rearers for conducting pre and post disinfection might also resulted in mortality of worm and thus reduced productivity (Table 5). Unavailability of required about of leaf in the vicinity of rearing house further aggravates the problem and the farmers have to transport leaf from far of places which they do quite unscientifically and by the time leaf is fed to the worms, it is already dry and nutritionally poor.

\section{Conflict of interest}

Authors would hereby like to declare that there is no conflict of interests that could possibly arise.

\section{References}

Central Silk Board CSB (2015) available on http://inserco.org/en/?q=statistics access on 11 October 2014.

Dhane V P, Dhane A V (2004) Constraints faced by the farmers in mulberry cultivation and silkworm rearing. Indian Journal of Sericulture 43: 155-159

Giridhar K, Mahanta JC, Nagesh S, Kantharaju BM (2011) Raw silk production : 2010-11. Indian Silk 2: 25-27
Gopala M, Krishna KS, Shivaramu K, Gokulraj MP (1992) A study on adoption of recommended silkworm rearing practices by farmers. Indian Silk 31: 25-26

Halakatti SV, Gowda DSM, Natikar KV (2010) Role of mass media in transfer of agricultural technologies. Research Journal of Agricultural Sciences 1: 290-291

Jayaram H, Indumati S (2010) Awareness, attitude and adoption of technological practices in sericulture - A discriminate function analysis. Indian Journal of Sericulture 49: 64-69

Moulik TK, Rao CSS (1965) Self rating scale for farmers. In: Measurement in Extension Research Instruments, New Delhi.

Shilpa CN, Nanjappa D, Krishnamurthy B (2011) A study on knowledge and adoption of potato growers in Hassan district of Karnataka. Research Journal of Agricultural Sciences 2: 699701

Sinha SS, Prasad BC, Ghosh S (1995). Sericultural extension in non-traditional areas. Indian Silk 34: 36-37

Srinivasa G, Doddagadad CB, Jayaram H, Geetha GS, Geetha Devi RG (1998) A logit function analysis of adoption behaviour of sericulturists in non-traditional area of Karnataka. Indian Journal of Sericulture 37: 163-166

State Sericulture Department (2015) available on http://jksericulture.nic.in/ access on $12^{\text {th }}$ October, 2014.

Sujatha B, Reddy PL, Naik SS, Sujathammaa P (2006) A study on adoption of recommended mulberry cultivation practices by sericulturists in Chittoor district of Andhra Pradesh. Indian Journal of Sericulture 45 : 142-148. 